\title{
Omalizumab as successful treatment option in severe peanut allergy
}

\author{
E Dehlink, C Bannert, ${ }^{*}$ T Eiwegger, S Diesner, S Gruber, Z Szépfalusi \\ From Food Allergy and Anaphylaxis Meeting (FAAM 2013) \\ Nice, France. 7-9 February 2013
}

\section{Background}

Peanut allergy is a potentially life threatening condition, which usually persists lifelong. Allergen avoidance is challenging as reactions often occur to traces of peanut in processed foods.

\section{Methods}

We present the case of a girl, who was diagnosed with peanut allergy at age 8 after she developed abdominal pain, urticaria and angioedema following a meal of cornflakes with peanut chips. No food challenge was performed at that time, and she was advised to avoid peanuts. Despite avoiding foods visibly containing peanut, she repeatedly experienced urticaria, burning of the tongue, nausea, and vomiting after consumption of different chocolates and ice creams. At age 13, she experienced a first episode of dyspnea and wheezing after eating a cake. This was when she was presented to our outpatient clinic.

\section{Results}

To confirm peanut allergy and to determine the allergen threshold dose, we performed open peanut challenge, during which she developed anaphylaxis that required epinephrine at a dose of $1.5 \mathrm{~g}$ of peanut, corresponding to one peanut. Because of the severity of the reaction and the repeated incidents despite elimination diet, we decided for a treatment with omalizumab, at a dose of $300 \mathrm{mg}$ every 4 weeks for 1 year, which was tolerated well by the patient. Four weeks after the last dose we repeated the open peanut challenge. The girl tolerated all doses with a cumulative dose of $5 \mathrm{~g}$, corresponding to 3 peanuts, without any symptoms. Total- and peanut-specific IgE levels remained unchanged, whereas titrated skin prick test reactivity slightly decreased. As a bystander effect, the girl's cat- and grass pollen allergy resolved completely.

\section{Department of Pediatrics and Adolescent Medicine, Medical University} Vienna, Vienna, Austria

\section{Conclusion}

Omalizumab is an effective and safe treatment option in severe peanut allergy.

\section{Disclosure of interest}

None declared.

Published: 25 July 2013

\section{doi:10.1186/2045-7022-3-S3-P20}

Cite this article as: Dehlink et al:: Omalizumab as successful treatment option in severe peanut allergy. Clinical and Translational Allergy 20133 (Suppl 3):P20.
Submit your next manuscript to BioMed Central and take full advantage of:

- Convenient online submission

- Thorough peer review

- No space constraints or color figure charges

- Immediate publication on acceptance

- Inclusion in PubMed, CAS, Scopus and Google Scholar

- Research which is freely available for redistribution
() Biomed Central 